\title{
Characterization of Health and Environmental Risks of Pesticide Use in Market-Gardening in the Rural City of Tori-Bossito in Benin, West Africa
}

\author{
Claude Ahouangninou ${ }^{1 *}$, Thibaud Martin ${ }^{2}$, Patrick Edorh ${ }^{3}$, Sahabi Bio-Bangana ${ }^{3}$, Onil Samuel ${ }^{4}$, \\ Louis St-Laurent ${ }^{4}$, Sylvain Dion ${ }^{5}$, Benjamin Fayomi ${ }^{1}$
}

${ }^{1}$ Institut des Sciences Biomédicales Appliquées, Université d'Abomey Calavi, Cotonou, Bénin; ${ }^{2}$ Cirad, UPR Hortsys, Montpellier, France; ${ }^{3}$ Centre Interfacultaire de Formation et de Recherche en Environnement pour le Développement Durable, Université d'Abomey Calavi, Cotonou, Bénin; ${ }^{4}$ Direction de la Santé Environnementale et de la Toxicologie, Institut National de Santé Publique du Québec, Québec, Canada; ${ }^{5}$ Direction du Secteur Agricole et des Pesticides, Ministère du Développement Durable, de l'Environnement et des Parcs, Québec, Canada.

Email: *cahoun83@yahoo.fr

Received January $1^{\text {st }}, 2012$; revised January $31^{\text {st }}, 2012$; accepted February $29^{\text {th }}, 2012$

\begin{abstract}
A study on the use of pesticides in market-gardening production was carried out on 108 market-gardeners in the rural city of Tori-Bossito in Southern Benin. The objective of the study was to characterize the potential risks of pesticides usage by farmers and the impacts on their health and on the environment. Two risk indexes were calculated for each pesticide: an environmental risk index (ERI) and a health risk index (HRI). First stage larva of the mosquito Aedes aegypti were used as bio-indicator for detecting insecticide residue in vegetable before their harvesting on the farms. The highest ERI were obtained for carbofuran, chlorpyriphos ethyl and endosulfan. Pesticide residues were found in $42 \%$ of the samples of leaves of eggplant, cucumber, amaranth and solanum. Vegetables growers used pesticides that may be highly hazardous and which were not registered in most cases. These situations could have unexpected consequences including the exposure of consumers to health hazards.
\end{abstract}

Keywords: Vegetable; Pesticide Residues; Bio-Indicator; Risk Index; Environment; Health

\section{Introduction}

Pesticides are increasingly used by farmers in Sub-Saharan Africa to protect their crops. Pesticides are used to destroy, neutralize insects, vermin, all kinds of human disease carriers, and other harmful or awkward plants or animal species. They help during the production, transformation, storage, transportation or distribution of foodstuffs, agricultural products, wood, and derived products. [1]. The use of these products requires some rules and procedures in order to avoid endangering human beings and the environment. Human health issues related to pesticide's use in agriculture have been noted in all regions of the world $[2,3]$. The environmental consequences related to the use of pesticides relate to things such as air quality, soil, water and biodiversity [4]. In West Africa, a pesticide contamination of the ground water was observed in farming area of Niayes in Senegal [5]. A contamination of ground water by the organophosphate and organochlorine pesticides was reported in several areas in Ivory Coast [6]. After the spreading of pesticide on ${ }^{*}$ Corresponding author. plants, the farmer generally needs to withdraw for some time (depending on the strength of the product) before harvesting in order to prevent the contamination of the crops. We noted however that this requirement is frequently bypassed. For instance, residues amounts exceeding $0.5 \mu \mathrm{g} / \mathrm{g}$ for the organochlorine (DDT, Endrin, Heptachlore) were detected in vegetables in SouthernBenin [7]. Like the majority of Sub-Saharan Africa farmers, those in the rural city of Tori-Bossito know little about the real toxicity of the pesticides and their sedentary use modes [8].

The aim of this study was to characterize by toxicological, ecotoxicological and biological indicators, the potential hazards for human health and the environment of the pesticides used by the small rural farmers of ToriBossito.

\section{Materials and Methods}

The study was carried out in the rural city of Tori-Bossito, located $30 \mathrm{~km}$ away from the city of Cotonou, in Southern Benin. It covers $328 \mathrm{~km}^{2}$ of land and has a huge 
area of mangroves which are very important for the farming and gardening activities in the region. We chose Tori-Bossito for this study because gardening is one of the primary income sources of the populations.

\subsection{Survey and Computation of the Risk Indexes}

A descriptive and analytical study was carried out to characterize the environmental and health risks related to the use of the agricultural pesticides in the rural city of Tori-Bossito. Hundred and eight gardeners were surveyed to obtain the information relative to pesticide usage in 2008. The information on the bottles and packaging of the pesticides were collected. Based on the information collected using the questionnaires and datas indexed in databases on the pesticides' toxicological and eco-toxicological properties, the health hazards and environmental risk indexes were calculated using the pesticides risk indicator of Quebec-IRPeQ developed by the Quebec National institute of public health (INSPQ), the Quebec ministry for Sustainable development, the Environment and the Parks (MDDEP) and the Quebec Ministry for Agriculture, Fisheries and Food (MAPAQ) [9]. The toxicological data used to compute the indexes was obtained in "The Manual E-Pesticide" (Wise \& Loveys Information Ltd Services, 2001) [10], in the European database on the properties of the pesticides "Footprint PPDB" [11] and in the database of "SAgE pesticides" developed by the INSPQ, the MDDEP and the MAPAQ [12]. The choice of the indicator of risks of the pesticides (IRPeQ) was made by considering the availability of the tool, its ease of use depending on data accessibility for the most active ingredients. IRPeQ calculates a human health risk index (HRI) and an environment risk index (ERI). The computation of the HRI considers all the toxicological properties of the active ingredients (acute toxicity, chronic toxicity modulated by a factor related with persistence and bio-accumulation) and certain properties of the commercial products (maximum amount recommended per hectare, and type of formulation). ERI incorporates the ecotoxicological impact of the active ingredients (a.i) on the terrestrial invertebrates, the birds, the aquatic creatures, and certain physio-chemical parameters (bio-accumulation, persistence in the ground and mobility).

$$
\begin{aligned}
& \mathrm{HRI}_{\text {active ingredient }}=\frac{\mathrm{TRI} * \mathrm{LFf} * \mathrm{FCP}}{10} \\
& \mathrm{ERI}_{\text {active ingredient }}=[1.75 *(T+O)+A+M+P+B+1]^{2} \\
& \mathrm{HRI}_{\text {pesticide }}=\sum \mathrm{HRI}_{\text {active ingredient }} \\
& \mathrm{ERI}_{\text {pesticide }}=\sum \mathrm{ERI}_{\text {active ingredient }}
\end{aligned}
$$

\subsection{Residual Amounts of Pesticides}

Samples of vegetable sheets and soils were taken to evaluate the presence of pesticide residues using a biological indicator of toxicity [13]. This method does not aim to identify the molecules present in samples, but at comparing the toxic effect of the extracts of sheets or soils on the first larvae stages of Aedes aegypti to the effect of a reference molecule, the deltamethrin, a crop protection agent recommended for commercial gardening in Benin. The deltamethrin was used as sentinel molecule because of its strong toxicity $\left(\mathrm{LD}_{50}\right.$ of $\left.0.4 \mu \mathrm{g} / \mathrm{L}\right)$ on the larvae of Aedes aegypti strain S-Be from north of Benin, but also because it belongs to the family of the pyrethrinoids. Indeed these insecticides are frequently used in Benin, either alone or combined with organophosphates, for crop protection [8].

In the market-gardening perimeters of Tori-Bossito, 24 samples of plant were taken in 17 parcels before harvest. Overall, 11 different plants were sampled. To evaluate the evolution over time of the amount of insecticide residue in the cabbage sheets and the surface layer of the ground after a treatment, samples of cabbage sheets and soils were taken one hour before and after treatment with DECIS $12.5 \mathrm{EC}$ to $35 \mathrm{~g}$ a.i/ha (active ingredient per hectare). Other daily samplings were conducted on the tenth day after treatment. For each sample, $200 \mathrm{mg}$ of vegetable or $60 \mathrm{mg}$ of soil were each put in a tube in which respectively $10 \mathrm{ml}$ and $40 \mathrm{ml}$ of ethanol were added to extract the residues from pesticides in 24 hours. A volume of $0.1 \mathrm{ml}$ of extract was added to the contents of a polystyrene goblet containing $9.9 \mathrm{ml}$ of water with 20 larvae of first stage of Aedes aegypti (with three repetitions for each sample). The counting of mortality was made 24 hours after application. The test was taken again with two dilutions $1 / 10$ and $1 / 100$ in the event of total mortality. Natural mortality was taken into account by tests with distilled water containing ethanol $1 \%$. A commercial formulation of Decis 12.5 EC made of deltamethrin with $12.5 \mathrm{~g} / \mathrm{L}$ was used to establish the calibration line on the larvae of Aedes aegypti. A dilution to the $1 / 200,000$ in distilled water was carried out before making a series of ten successive dilutions giving a mortality ranging between 1\% and 99\% (Figure 1). The residual amount of pesticides in the vegetable sheets was evaluated and recorded in microgram per gram of equivalentdeltamethrin starting from the calibration curve.

\section{Results}

\subsection{Human Health and Environmental Risks of the Pesticides}

Health Risks Indexes (HRI)

In the results of our analysis, some active ingredients 
such as endosulfan, chlorpyriphos-ethyl and maneb presented simultaneously high acute and chronic risks (Table 1).

Others like lambdacyhalothrin, acetamiprid, metalaxyl and copper oxyd presented a high acute risk, but a weak chronic risk. Active ingredients such as mancozeb, carbendazim, thiophanate-methyl presented a high chronic risk and a weak acute risk. The maneb and the acetamiprid gave the weakest factor related to persistence in the environment and the bio-accumulation on human. The highest toxicological risk indexes (TRI) and the highest health risk indexes (HRI) were obtained for endosulfan, chlorpyriphos-ethyl and mancozeb (Table 2). As far as the commercial preparations are concerned, there are the formulations of endosulfan (COTOFAN 350.EC and THIONEX 350.EC), of chlorpyriphos-ethyl (DURSBAN) and the mancozeb (FOKO) which presented the highest risks for the human health with respectively indexes of 2290, 3499 and 3538 (Table 3). Formulations of DECIS 12.EC, TOPSIN M and the COTALM P 218.EC had a slightly lower risk level. The formulation of COTALM P 218.EC was the most used by the producers of ToriBossito ( $84.2 \%$ of the vegetable growers). The fungicide CALLOMIL 72WP (metalaxyl and copper oxyd) presented the lowest risk of health impact.

\subsection{Potential Presence of Residues of Pesticide in the Samples Analysis}

The impact of the deltamethrin on the first stage larvae of Aedes aegypti is illustrated by Figure 1. The mortality of the larvae was observable starting from $0.1 \mu \mathrm{g} / \mathrm{L}$ of deltamethrin. Mortality was total from $1 \mu \mathrm{g} / \mathrm{L}$ of deltamethrin. The results of the vegetables samples taken on plants before harvest showed the potential presence of residues of pesticides in $41.7 \%$ of the collected samples (Table 4 ).

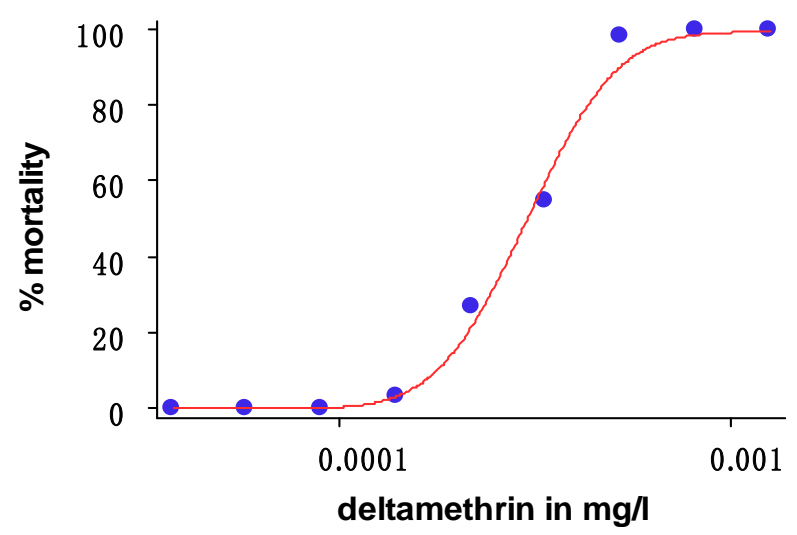

Figure 1. Toxicity of deltamethrin (DECIS 12.5 EC) on Aedes aegypti L1 larva (S-Be strain).

Table 1. Values of the parameters entering in calculation of health risk index.

\begin{tabular}{lccccccc}
\hline Actives ingredients & Acute risks & Chronic risks & Fper & LFf & FCP & TRI & HRI \\
\hline Endosulfan & 20 & 29 & 3 & 2 & 1 & 11,449 & 2290 \\
Lambdacyhalothrin & 40 & 2 & 3 & 2 & 0.5 & 2116 & 212 \\
Cyperméthrin & 16 & 25 & 3 & 2 & 0.5 & 8281 & 828 \\
Acetamiprid & 24 & 4 & 1 & 2 & 0.5 & 784 & 78 \\
Chlorpyriphos-ethyl & 22 & 37 & 3 & 2 & 1 & 17,689 & 3538 \\
Profenophos & 18 & 18 & 3 & 2 & 1 & 5184 & 1037 \\
Deltamethrin & 14 & 37 & 3 & 2 & 1 & 15,625 & 1562 \\
Cyfluthrin & 15 & 26 & 2.5 & 2 & 0.5 & 6400 & 640 \\
Mancozeb & 8 & 50 & 2 & 2 & 1.5 & 11,664 & 3499 \\
Carbofuran & 18 & 25 & 2 & 1 & 2 & 4624 & 925 \\
Carbendazim & 4 & 41 & 2 & 2 & 1 & 7396 & 1479 \\
Metalaxyl & 21 & 1 & 2.5 & 2 & 1 & 552 & 110 \\
Cooper oxyd & 24 & 3 & 3 & 2 & 1 & 1089 & 218 \\
Thiophanate-methyl & 7 & 38 & 2 & 2 & 1 & 6889 & 1378 \\
Maneb & 20 & 53 & 1 & 2 & 1.5 & 5329 & 1599 \\
\hline
\end{tabular}

Fper: Factor taking into account the persistence and the potential of bio-accumulation in human; LFf: Loading factor related to the type of formulation; FCP: Factor of compensation taking into account the concentration of the active ingredient in the formulation as well as the dose recommended per hectare; TRI: Toxicological Risk Index; HRI: Health Risk Index. 
Table 2. Values of the parameters entering in calculation of environment risk index.

\begin{tabular}{lccccccc}
\hline Actives ingredients & T & $\mathbf{O}$ & $\mathbf{A}$ & $\mathbf{M}$ & $\mathbf{P}$ & $\mathbf{B}$ & IRE \\
\hline Endosulfan & 4 & 2 & 4 & 0 & 2 & 2 & 380 \\
Lambdacyhalothrin & 0 & 0 & 3 & 0 & 0 & 2 & 36 \\
Cyperméthrin & 4 & 0 & 4 & 0 & 1.5 & 2 & 240 \\
Acetamiprid & 2 & 2 & 0 & 0 & 0 & 0 & 12 \\
Chlorpyriphos-ethyl & 4 & 3 & 4 & 0 & 1 & 2 & 410 \\
Profenophos & 4 & 2 & 3 & 0 & 0 & 0 & 210 \\
Deltamethrin & 4 & 0 & 3 & 0 & 0 & 2 & 169 \\
Cyfluthrin & 4 & 0 & 4 & 0 & 0.5 & 2 & 210 \\
Mancozeb & 0 & 0 & 4 & 0 & 0.5 & 0 & 30 \\
Carbofuran & 4 & 4 & 4 & 4 & 1 & 0 & 576 \\
Carbendazim & 4 & 0 & 3 & 1.5 & 0 & 0 & 156 \\
Metalaxyl & 0 & 0 & 0 & 1.5 & 1 & 0 & 12 \\
Cooper oxyd & 0 & 0 & 2 & 0 & 4 & 0 & 49 \\
Thiophanate-methyl & 2 & 0 & 1 & 0 & 0 & 0 & 30 \\
Maneb & 0 & 0 & 3 & 0 & 0 & 0 & 16 \\
\hline
\end{tabular}

T: Impact on the terrestrial invertebrates; O: Impact on birds; A: Impact on the watering organisms; M: Mobility of the active ingredient; P: Persistence in the soil; B: Bio-accumulation; ERI: Environmental Risk Index.

Table 3. Environment and Health risks indexes of pesticides.

\begin{tabular}{|c|c|c|c|c|}
\hline Pesticides & Actives ingredients & Farmer's use level (\%) & HRI & ERI \\
\hline DIAFURAN & Carbofuran & 2.8 & 925 & 576 \\
\hline \multirow[t]{2}{*}{ CYFLUTHRALM P318EC } & Cyfluthrin & 0.9 & 1677 & 420 \\
\hline & Profenofos & & & \\
\hline DURSBAN & Chlorpyriphos-ethyl & 0.9 & 3538 & 410 \\
\hline COTOFAN 350EC & Endosulfan & 3.7 & 2290 & 380 \\
\hline THIONEX 350EC & Endosulfan & 0.9 & 2290 & 380 \\
\hline \multirow[t]{2}{*}{ CAPT 88EC } & Cypermethrin & 1.9 & 906 & 252 \\
\hline & Acetamiprid & & & \\
\hline \multirow[t]{2}{*}{ COTALM P218EC } & Lambdacyhalothrin & 84.2 & 1249 & 246 \\
\hline & Profenofos & & & \\
\hline CYPERCAL 50EC & Cypermethrin & 3.7 & 828 & 240 \\
\hline CYDIM C50 & Cypermethrin & 0.9 & 828 & 240 \\
\hline CYPER D & Cypermethrin & 0.9 & 828 & 240 \\
\hline DECIS 15EC & Deltamethrin & 4.6 & 1562 & 169 \\
\hline BENDAZIM 50WP & Carbendazim & 1.9 & 1479 & 156 \\
\hline \multirow[t]{2}{*}{ CALLOMILL 72WP } & Metalaxyl & 1.9 & 328 & 61 \\
\hline & Cooper oxyd & & & \\
\hline TOPSIN M & Thiophanate-methyl & 29.6 & 1378 & 30 \\
\hline FOKO & Mancozeb & 33.3 & 3499 & 30 \\
\hline TRIMANGOL 80 & Maneb & 0.9 & 1599 & 16 \\
\hline IVORY & Maneb & 1.9 & 1599 & 16 \\
\hline
\end{tabular}


Table 4. Estimation of pesticide residues (in $\mathrm{mg}$ of equivalent deltamethrin per $\mathrm{kg}$ of leave) in 24 samples of leaves from 11 plants before harvest in 4 market-gardening in Tori-Bossito.

\begin{tabular}{lcccc}
\hline \multirow{2}{*}{ Samples } & \multicolumn{4}{c}{ Market-gardening perimeters of Tori-Bossito } \\
\cline { 2 - 5 } Cabbage & Hla & Dohinoko & Ananvié & Houédaga \\
Solanum & 0.03 & - & - & - \\
Eggplant & $\mathrm{Nd}$ & - & - & 4.75 \\
Cucumber & $\mathrm{Nd}$ & - & 1.17 & 0.04 \\
Bean & $0.07-0.11$ & - & - & - \\
Zucchnini & $\mathrm{Nd}$ & - & - & - \\
Celosia & $\mathrm{Nd}$ & - & - & - \\
Amaranth & - & 0.09 & - & - \\
Vernonique & - & $0.04-0.07$ & - & - \\
Squeaky fiddle & - & $\mathrm{Nd}$ & - & - \\
Tomato & - & $\mathrm{Nd}$ & - & - \\
\hline
\end{tabular}

${ }^{*} \mathrm{Nd}$ : Not detected, residual insecticide content expressed mg of deltaméthrine/kg equivalent of leaves.

The most important residual amounts were found in sheets of eggplant and solanum (respectively 1.17 and $4.75 \mathrm{ppm}$ of equivalent-deltamethrin). In the other positive samples coming from both traditional vegetables (amaranthe, celosy, solanum) and "exotic" vegetables (cabbage, tomato, eggplant, cucumber), the amounts were lower than 0.1 ppm of equivalent-deltamethrin.

One hour before the spreading of the DECIS 12.5 EC, no residue of pesticide was detected in the samples of sheets of cabbages and soils (Figure 2). One hour after treatment, the residual amount of deltamethrin detected in the cabbage sheets was about $500 \mathrm{ppb}$ (ng/g of sheets) and of $90 \mathrm{ppb}$ ( $\mathrm{ng} / \mathrm{g}$ of soils) in the soils. This residual amount of deltamethrin decreased regularly with time to reach $8 \mathrm{ppb}$ at the end of 10 days. In the samples of soils, the amount of deltamethrin remained stable until the second day after treatment. Beyond two days after treatment, no insecticide residue was detected in the soils.

\section{Discussions}

\subsection{Evaluation of the Environmental and Health Risks of the Pesticides}

The indicator of risk for the environment showed the carbofuran as being the most dangerous product for the environment among all the listed active ingredients. Moreover, a high quantity of the active ingredient must be used ( $5 \mathrm{~kg} \mathrm{ma} / \mathrm{ha})$ for an effective stabilization of soils against nematodes, according to the inscriptions present on packaging. According to the surveyed vegetable growers, Carbofuran is the only nematicide product available in Benin. ERI confirmed that Carbofuran actually belongs to the $1 \mathrm{~b}$ category (highly dangerous) of the World Health Organization (WHO) pesticides classification [14].

ERI also classified chlorpyriphos-ethyl and Endosulfan as dangerous for the environment after Carbofuran. Endosulfan was recently prohibited in Benin like in most Sub-Saharan African countries, especially the members of the Inter-State Committee for the Fight against Dryness in the Sahel (CILSS) [15]. It is very neurotoxic and was classified in the Ib category (very highly dangerous) by the US EPA [16] and in category II (moderately dangerous) by WHO [14]. Cases of intoxication and deaths were blamed on Endosulfan in Benin [17]. Acetamiprid is classified as the least dangerous for the environment. Nevertheless, its use is risky for birds and terrestrial invertebrates such as the bees $[10,11]$.

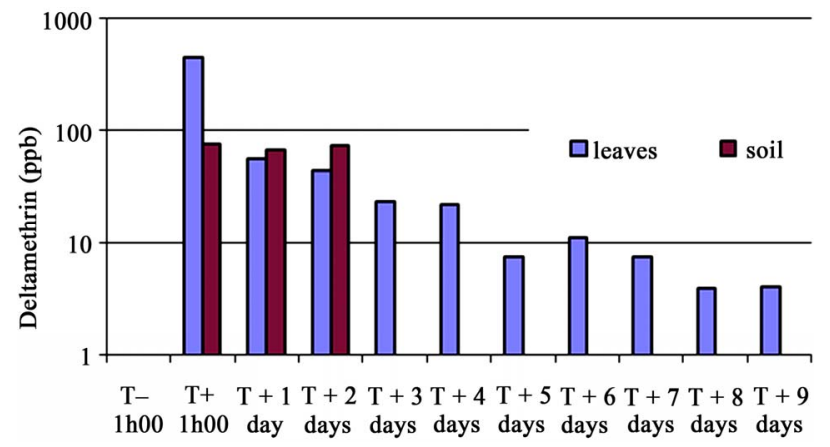

Figure 2. Residual quantity of deltamethrin in cabbage plots and soils after a spray (T) with Decis 12.5 EC at $35 \mathrm{~g}$ a.i./ha. 
The HRI classified Mancozeb, Chlorpyriphos-ethyl and Endosulfan as very risky for producers and consumers' health. These active ingredients have both a high chronic toxicity risks and a high potential of bio-accumulation on human. Mancozeb was used by one third of the producers as a fungicide. Regular exposure to this active ingredient could induce occupational diseases in the long run. Indeed Mancozeb has a strong environmental persistence and a high potential of bio-accumulation. It is genotoxic and could have an impact on human reproduction [18]. It could be replaced by biological fungicides such as Bacillus subtilis which would equally fight diseases induced by mushrooms [19].

COTALM P218EC (mixture of lambdacyhalothrin and profenofos) presents a health and environmental hazard relatively lower in comparison with formulations of endosulfan and chlorpyriphos-ethyl which have a higher risk of acute toxicity (high eyepiece and cutaneous irritation). It is riskier for birds, terrestrial and aquatic living things. It is used by producers because of its low cost but also for its broad spectrum of activity. Lambdacyhalothrin like any pyrethrinoid has also a toxic and repulsive effect on useful insects (parasitoïdes): this increases the risk of vermin's overpopulation. It would be preferable to replace it with Spinosad (Laser), a bio-insecticide frequently used on tomato in Benin.

IRPeQ enabled us to calculate the environmental and health risk in relation to the amounts applied per hectare. For the calculation of ERI, the ecotoxicological properties were taken into account to estimate the impact of the active ingredients on aquatic creatures, invertebrates and birds. It also considers several physico-chemical parameters such as mobility, persistence in the ground, bio-accumulation and other characteristics related to the commercial preparation. For the calculation of the HRI, the acute and chronic toxicological characteristics, environmental persistence and the potential of bio-accumulation of the products are considered. Next, the types of formulation and equipment come to modulate the health hazard. This indicator allows us to compare various pesticides, and make decisions based on environmental and public health criteria [9]. This indicator can be modified according to whether it is used for provincial assessments or on the farm. In the first case, the risks indexes are calculated on the basis of the reference amount applied per hectare whereas in the case of application to the farm, the module IRPeQ-express let the farmers integrate the actual quantity used in their calculation [20]. This module is distinct but complementary to the "SAgEpesticides" which wants to be especially a tool facilitating the choice of low-risks pesticides. IRPeQ also accounts for the drift and the height of vegetation in the ERI computation. IRPeQ considers that the good practices are respected by the workers so for instance, it won't assess whether or not, growers are wearing protective gears. This variable can easily be integrated into an exercise of risks analysis referring to various scenarios of exposure without being a decision-making tool. The model can however be updated to adapt to techniques used in tropical Africa where some producers ignore the measurements and safety rules, and simply use branches of plants to sprinkle the insecticidal pulp and thus to make possible to quantify the risk for a producer [8]. One limitation of the risk indicators is that the underlying data is not available for all the active ingredients. This was also mentioned by [21]. Due to the lack of clearly defined benchmarks for the risk indicators, the results obtained by score aggregation will lack traceability and make it hard to statute on whether or not a product is safe for use [22]. They however let you compare active ingredients and commercial preparations to choose the least risky for human health and environment. The same active ingredient in two different commercial preparations can have different environmental and health risks indexes because guidelines and reference amounts vary for each commercial preparation. Sometimes, entry variables are highly weighted [22,23]. IRPeQ however doesn't overweight certain variables compared to others. It is a complex indicator which aggregates the scores of several parameters to accurately depict reality.

\subsection{Biological Method of Detection of Pesticides Residues}

The strongest residual amounts of pesticides were found in samples of eggplant and solanum (respectively 1.17 and $4.75 \mathrm{ppm}$ of equivalent-deltamethrin). To draw a comparison with food poisoning risk, these doses exceed the maximum limit of residue in vegetables accepted in the European Union for deltamethrin (approximately 0.5 ppm) [24]. One explanation may be that these plants were treated with other active ingredients a few days before the samples were taken. The biological indicator used found traces of residual contents ( 5 to $10 \mathrm{ppb}$ of deltamethrin) up to 10 days after a treatment in spite of the water-spraying carried out twice everyday (morning and evening). These make it a sensitive indicator in addition to being inexpensive. A little less than half of the vegetable samples contained less than $0.5 \mathrm{ppm}$ of deltamethrin equivalent. This represents an intoxication threat. The amounts can be underestimated if the growers use pesticides less toxic than deltamethrin on Aedes aegypti larvae. Generally the producers sell these vegetables to wholesalers or retailers who made them directly available to consumers. It's therefore very important to educate buyers about the importance of washing thoroughly the vegetables before consumption. The longer the lifespan of the pesticide, the higher are its risks. The 
residues of pesticides are not detected in the samples of soils beyond two days after spreading of the DECIS 12.5EC. This could be explained by the sandy nature of the soil and frequent irrigation. But the absence of residues in the soils doesn't mean that these molecules were destroyed. By infiltration they could have infiltrated the groundwater and thereby jeopardize water quality. This biological pesticides residues detection method is used only as indicator of pollution because it doesn't reveal the active ingredients contained in the samples [13]. It could be coupled to more expensive but more precise methods of analysis such as chromatography coupled with mass spectrometry $[7,25,26]$. The method only detects residues having a lethal effect on the larvae of Aedes aegypti. Considering the fact that pyrethrinoid are used by almost $85 \%$ of producers in Tori-Bossito and that the larva of Aedes aegypti is very sensitive to these products, we could infer that these plant health products contribute to the toxicity observed in the larvae. It becomes therefore critical from a public health stand-point to educate the vegetable growers on the risks of the plant health products.

\section{Conclusion}

Our investigation enabled us to identify the formulations of pesticides used in commercial gardening and to target those with a high potential impact on human health and on the environment. The pesticides having the highest risks were also the least frequently used. The biological method of detection indicates the potential presence of residues of pesticides in certain samples of vegetables. Frequent analysis of residues of pesticides with methods of analytical chemistry will enhance the specificity of the observed results. For the safety of the producers, distributors and consumers, it appears necessary that public authorities pay a closer attention to the marketing and use of plant health products and develop alternatives methods like the physical fight $[27,28]$.

\section{Acknowledgements}

We sincerely thank the Entomological Research center and the Research institute for Development-Unit 016 in Cotonou, the authorities of the Agricultural Sector and Pesticides Division of the Ministry of Sustainable Development, Environment and the Parks of Quebec, the Management of the Environmental Health and Toxicology of the National Institute of Public Health of Quebec for their support and their contribution to this work.

\section{REFERENCES}

[1] FAO, "International Code of Conduct on the Distribution and Use of Pesticides," FAO, Rome, 1986.
[2] M. Sanborn, D. Cole, K. Kerr, C. Akil, L. H. Sanin and K. Bassil, "Pesticides Literature Review," Ontario College of Family Physicians, Toronto, 2004.

[3] J. A. Tomenson and G. A. Matthews, "Causes and Types of Health Effects during the Use of Crop Protection Chemicals: Data from a Survey of over 6300 Smallholder Applicators in 24 Different Countries," International Archives of Occupational Environmental Health, Vol. 82, No. 8, 2009, pp. 935-949. doi:10.1007/s00420-009-0399-4

[4] D. Pimentel, H. Acquay, M. Biltonem, P. Rice, M. Silva, J. Nelson, S. Lipner, S. Giordan, A. Horowitz and M. D'Amore, "Assessment of Environmental and Economic Impacts of Pesticide Use," In: D. Pimentel and H. Lehman, Eds., The Pesticides Question, Environment, Economics and Ethics, Routledge, Chapman and Hall, New York, 1993.

[5] I. Cissé, A. A. Tandia, S. T. Fall and E. H. S. Diop, "Usage Incontrôlé des Pesticides en Agriculture Périurbaine: Cas de la Zone de Niayes au Sénégal," Cahiers Agricultures, Vol. 12, No. 3, 2003, pp. 181-186.

[6] S. K. Traoré, K. Mamadou, A. Dembele, P. Lafrance, P. Mazelliert and P. Houenou, "Contamination de l'Eau Souterraine par les Pesticides en Régions Agricoles en Côte-d'Ivoire (Centre, Sud et Sud Ouest)," Journal Africain des Sciences de l'Environnement, Vol. 1, 2006, pp. 1-9.

[7] F. Assogba-Komlan, P. Anihouvi, E. Achigan, R. Sikirou, A. Boko, C. Adje, V. Ahle, R. Vodouhe and A. Assa, "Pratiques Culturales et Teneur en Eléments Antinutritionnels (Nitrates et pesticides) du Solanum macrocarpon au Sud du Bénin," Africain Journal of Food, Agriculture, Nutrition and Developement, Vol. 7, 2007, pp. 1-21.

[8] C. Ahouangninou, B. E. Fayomi and T. Martin, "Evaluation des Risques Sanitaires et Environnementaux des Pratiques Phytosanitaires des Producteurs Maraîchers dans la Commune Rurale de Tori-Bossito (Sud-Bénin)," Cahiers Agricultures, Vol. 20, No. 3, 2011, pp. 216-222. doi:10.1684/agr.2011.0485

[9] O. Samuel, S. Dion, L. St Laurent and M. H. April, "Indicateur de Risque des Pesticides du Québec-IRPeQ Santé et Environnement Québec," Ministère de l'Agriculture, des Pêcheries et de l'Alimentation/Ministère de Développement Durable, de l'Environnement et des Parcs/Institut National de Santé Publique du Québec, Québec, 2007

[10] Wise \& Loveys Information Services Ltd., "The e-Pesticide Manual 2000-2001 (Twelve Edition)," Version 2.0 Editor: CDS Tomlin; British Crop Protection Council.

[11] University of Hertfordshire, "Base de Données FOOTPRINT PPDB sur les Propriétés des Pesticides," FOOTPRINT: Des Outils Innovant Pour l'Evaluation et la Réduction du Risque Pesticides, 2008, http://www.eu-footprint.org/fr/ppdb.html

[12] Ministère de l'Agriculture, des Pêcheries et de l'Alimentation du Québec, "Base de données SAgE Pesticides," 2009. http://www.sagepesticides.qc.ca/

[13] T. Martin, F. Chandre, J. Chabi, P. F. Guillet, M. Akog- 
beto and J. M. Hougard, "A Biological Test to Quantify Pyrethrinoid in Impregnated Nets," Tropical Medicine and International Health, Vol. 12, No. 2, 2007, pp. 1-6.

[14] WHO, "The WHO Recommended Classification of Pesticides by Hazard and Guidelines to Classification," 2005. http://www.who.int/ipcs/publications/pesticides_hazard_r ev_3.pdf

[15] PAN and IPEN, "Interdiction de l'Endosulfan dans les Pays du Sahel en Afrique de l'Ouest," Octobre 2008.

[16] US EPA, "Reregistration Eligibility Decision for Endosulfan," November 2002.

[17] P. Ton, S. Tovigan and S. D. Vodouhe, "Intoxications et Morts au Bénin par l'Endosulfan," In: Pesticides \& Alternatives. Bulletin de Pesticide Action Network Africa, N. 10-Avril, 2000.

[18] N. Bonnard, D. Jargot, M. Falcy, A. Fastier, S. Oudar and M. O. Rambourg, "Mancozèbe. Fiche Toxicologique," INRS/AFSSA, France, 2010, 8 Pages.

[19] K. Hibar, M. Daami-Remadi and M. El Mahjoud, "Effets de Certains Fongicides de Synthèse et Biologiques sur la Croissance Mycélienne et l'Agressivité de Fusarium oxysporium f. sp. radicis-lycopersici," Tropicultura, Vol. 25, 2007, pp. 146-152.

[20] K. Boutin, J. Champagne and K. Grenier, "Indice de Risque et Registre des Pesticides SECTEUR AGRICOLE (IRPeQ-Express),” 2009. http://www.irpeqexpress.qc.ca/

[21] H. M. G. Van der Werf, "Assessing the Impact of Pesticides on the Environment," Agriculture, Ecosystems and Environment, Vol. 60, No. 2, 1996, pp. 81-96.

[22] J. Devillers, R. Farret, P. Girardin, J. L. Rivière and G. Soulas, "Indicateurs Pour Evaluer les Risques Liés à l'Utilisation des Pesticides,'Editions Tec\&Doc Lavoisier, Paris, 2007.
[23] F. Giuseppe, E. Rahn and C. R. Binder, "Testing Environmental and Health Pesticide Use Risk Indicators, the Case of Potato Production in Boyacá, Colombia," Conference on International Research on Food Security, Natural Resources Management and Rural Development, Zurich, September 2010, Tropentag 2010, pp. 14-16. http://www.tropentag.de/2010/abstracts/full/266.pdf

[24] UE, “Journal Officiel de l'Union Européenne,” Législation du 28 mai 2011. http://publications.europa.eu/others/agents/index_fr.htm

[25] E. Y. A. Pazou, M. Boko, C. A. M. Van Gestel, H. Ahissou, P. Laleye, S. Akpona, B. Van Hattum, K. Swart and N. M. Van Straalen, "Organochlorine and Organophosphorous Pesticide Residues in the Ouémé River Catchment in the Republic of Benin," Environment International, Vol. 32, No. 5, 2006, pp. 616-623.

[26] E. Y. A. Pazou, P. Laleye, M. Boko, C. A. M. Van Gestel, H. Ahissou, S. Akpona, B. Van Hattum, K. Swart and N. M. Van Straalen, "Contamination of Fish by Organochlorine Pesticide Residues in the Ouémé River Catchment in the Republic of Bénin," Environment International, Vol. 32, 2006, pp. 594-599.

[27] T. Martin, F. Assogba-Komlan, T. Houndete, J. M. Hougard and F. Chandre, "Efficacy of Mosquito Netting for Sustainable Small Holders' Cabbage Production in Africa," Journal of Economic Entomology, Vol. 99, No. 2, 2006, pp. 450-454. doi:10.1603/0022-0493-99.2.450

[28] S. Licciardi, F. Assogba-Komlan, I. Sidick, F. Chandre, J. M. Hougard and T. Martin, "A Temporary Tunnel Screen as an Eco-Friendly Method for Small-Scale Growers to Protect Cabbage Crop in Benin," International Journal of Tropical Insect Science, Vol. 27, No. 3-4, 2007, pp. 152158. 